\title{
Evaluation of Software and Architectural Design Requirement Specifications for Developing an Intelligent Tutor System for Learning Computer Networking in Universities in Nigeria
}

\author{
Ezenma Chimezie Bernard, Onah Ifeoma Bernadine*, Eze Blessing Ngozi, \\ Onyemachi Chinedu Okechukwu, Onyedimara Justina Prisca Amara
}

Department of Computer and Robotics Education, Faculty of Technical and Vocational Education, University of Nigeria, Nigeria

Received June 23, 2020; Revised August 4, 2020; Accepted August 25, 2020

\section{Cite This Paper in the following Citation Styles}

(a): [1] Ezenma Chimezie Bernard, Onah Ifeoma Bernadine, Eze Blessing Ngozi, Onyemachi Chinedu Okechukwu, Onyedimara Justina Prisca Amara, "Evaluation of Software and Architectural Design Requirement Specifications for Developing an Intelligent Tutor System for Learning Computer Networking in Universities in Nigeria," Universal Journal of Educational Research, Vol. 8, No. 10, pp. 4634-4641, 2020. DOI: 10.13189/ujer.2020.081032.

(b): Ezenma Chimezie Bernard, Onah Ifeoma Bernadine, Eze Blessing Ngozi, Onyemachi Chinedu Okechukwu, Onyedimara Justina Prisca Amara (2020). Evaluation of Software and Architectural Design Requirement Specifications for Developing an Intelligent Tutor System for Learning Computer Networking in Universities in Nigeria. Universal Journal of Educational Research, 8(10), 4634-4641. DOI: 10.13189/ujer.2020.081032.

Copyright $\bigcirc 2020$ by authors, all rights reserved. Authors agree that this article remains permanently open access under the terms of the Creative Commons Attribution License 4.0 International License

\begin{abstract}
The purpose of this study is to evaluate software and architectural design requirement specifications for developing an intelligent tutor system (ITS) for learning computer networking. This study adopted survey design with a total population of 73 computer lecturers and 16 software developers. A structured questionnaire was used to obtain data from lecturers and software developers. Data collected was analyzed using mean and standard deviation to determine the appropriate software and architectural design requirement specifications for developing a tutor system for learning computer networking. It was observed that the enlisted software and architectural design requirement particularly for students are appropriate for developing an ITS for learning computer networking. Therefore, the proposed intelligent tutor system to be developed will provide and allow computer education students to improve their computer networking knowledge. Thus, improving learners' performance and cognitive development reduce time for the student to acquire skills and knowledge and bridge the gap of face to face interaction between lecturers and students, which will equally improve self-pace learning.
\end{abstract}

Keywords Intelligent Tutor System, ITS Requirement Specifications, ITS Architectural Design Requirements, Computer Networking

\section{Introduction}

The development of intelligent tutor system is growing very rapidly and this is one of the reasons why the system and architectural requirement specifications are very important to be considered and develop massively (Rabiman, Muhammad, Nur, 2020). As more instruction moves online, to offer learning resources to distance learning students or to offer asynchronous education at the learner's point of needs (Ariel, 2020). It is essential to attend to the needs of the learners and the varying needs of the whole students by taking the system and architectural requirement specifications into consideration (Ali \& İsmail, 2020). Furthermore, a lot of innovative learning software are in place, like tutoring system that provides instructions to learners at anytime and anywhere (Viberg and Grönlund 2017); digital game-based training system that motivates 
continues learning (Sirin et al. 2018); and personalized, flexible and coaching systems for tailored instruction (Taub and Azevedo 2019). In the context of this study, finding from the preliminary study conducted on assessment of computer networking needs of students of computer education and industrial technical education for improving academic performance in Nigeria Universities (Onah, Ezenma, Ariyo, Jimoh, Omeje, Okereke, Ogbonna, Ogbu and Mukoro, 2020) revealed that lecturers have not been using an intelligent tutor system in Universities in Nigeria for teaching and learning computer networking. Moreover, the study also revealed that students need ITS that will provide self-pace learning and improve their academic performance on computer networking course. Therefore, this study is aimed at evaluating the software and architectural design requirement specifications for developing an intelligent tutor system for learning computer networking. Specifically, the study tends to: determine the software administrators' functional requirements for developing an intelligent tutor system, the architecture user case design requirement specifications for developing an intelligent tutor system and the students' learning content requirements for developing an intelligent tutor system for learning computer networking.

\section{Intelligent Tutor System}

When it comes to teaching and learning, intelligent tutor system has contributed immensely to supporting lecturers to coach and gain innovative skill. Mostly, these are medium of using Information technology to deliver learning resource; audio information technology means, visual information technology means and audiovisual means, for instance computer and Smartphone applications (Sodhro, Luo, Sangaiah, Baik, 2018). Intelligent Tutoring Systems uses tech-based information system to deliver diverse learning style and instructional contents to students (Ali \& İsmail, 2020). Educational coaching system is a novel educational podium that utilizes digital technology to enhance learners' speed of learning by providing instructions, tests, video and exercises (Jiragorn, Prachyanun, Panita, 2019). An intelligent tutor system contains learning resources and delivers it to them. This system adopts a systematic procedure with respect to learning ethics and provides personalized lesson that meets personal requirements and intellect of students. The basic attributes of a coaching software are creating of (i) what is to learn that are associated with students existing information so as to encourage greater understanding (ii) personalized response mechanism that will arouse next learning activities and avoid frustration and demonization as a result of poor performance, and (iii) direction that will aid students to solve their individual exercises (Maiga, Giuseppe, Matteo, Francesco, Demetrios, Carmine, 2020). It can be applied to enhanced pedagogy and improvement of learners' logical knowledge and knowledge of their perception of personalized education that enhance learners to get information and utilizes information system to generate potential systems (Jiragorn, Prachyanun, Panita, 2019).

Mones, Mohammed, Samy (2017) designed and developed an ITS for teaching computer networks. The ITS provided different architectures to support ITS for learning computer networks. Ali, Ahmed, Basma (2018) presented an ITS for coaching senior students an introduction to networking. The outcome indicated no disparity in the performance in the Pre-Test while there was an improvement to the students who used this ITS and those who did not use it. Karsten (2019) designed PQtutoraquasi-coaching system for quantitative problems in Chemistry to supplement the already reading culture from Chemistry textbook. Thus, Santiago, Christian, David, Carlos, Miguel (2020) proposes a coaching system that makes programming to be learnt easily by applying dynamic graphic visualizations. Daniel, Erik, Kenneth (2020) proposed a novel interaction design for developing an intelligent tutoring systems by training simulated learners. The novel interaction design helped students in creating model-tracing complete ITSs in less than a quarter of the time it would have taken to author the same ITSs with CTAT example-tracing.

However, the above literature on intelligent tutors indicates that there has not been an ITS for teaching and learning of computer networking course in computer education departments in Nigeria Universities. This was ascertained from thepreliminary study conducted by the researchers on assessment of computer networking needs of students of computer education and industrial technical education for improving academic performance in Nigeria Universities (Onah, Ezenma, Ariyo, Jimoh, Omeje, Okereke, Ogbonna, Ogbu and Mukoro, 2020). Consequently, in order to fill this gap and enhance the flexibility, usage and understanding the course "computer networking", evaluating the system and architectural design of an intelligent system for teaching and learning computer networking will help bridge the gap of face to face interaction between lecturers and students, which will equally improve self pace learning.

\section{Intelligent Tutor System Requirement Specifications}

The requirement stage in an intelligent tutor system development emphasizes more on the feasibility study aspect activities which includes: setting up development group, establishing the reason, extent and finding out the difficulties that are involved in system development, identifying and assessing techniques to be adopted during the developmental process (Suryanto, Sigit, \&Luqman, 2017).In the requirement phase, this phase aims to spot out the learning need earlier before the intelligent tutor system development is carried out (Rabiman, Muhammad, Nur, 
2020). Once the appropriate body approves the requirements from the feasibility study, then the development can commence (Marakas, James \& George, 2010). During the developmental process there are stages in which the developer should follow such as collection of fact, security of the present system and analysis of the proposed system (Control and Audit, Information Systems, 2013). The requirements specifications for this computer networking intelligent tutor system covers: software, administrators, students and architectural requirement specification. These requirements were gathered and analyzed from teachers and software developers, and the specifications were documented against designing the software according to the software requirement specifications.

\section{Intelligent Tutor System Architectural Design}

The architectural design defines the plan for a solution by considering the high-level design that has satisfied the whole learners' needs. It is the responsibility of the system analysts to convert the high-level design to the visible plan by taking hardware and software technology into consideration. Intelligent tutor system architecture is defined at design stage as well (Yan, Wong, 2016). Software architecture helps in explaining the requirement specifications and divides it into manageable and transferable components (Nikolaj and Alke, 2020). This reduces error so that implemented system avoids common errors. The standard model of ITS architecture has four major models which are the domain model, student model, tutoring model and user interface model (Fehaid, \&Naeem, 2019).

\subsection{Domain Model Architecture}

The domain model architecture consists of the concepts, facts, rules, and problem-solving strategies of what is to be taught (Kee, 2011). The author further explained that it is regarded as the part that supplies learning resources, a usual means for assessing student's level of understanding and determines the student's likely response to tutorial actions. The domain model contains what to learn and the procedures in which it should be followed by the learners (Ahmad, 2019). The domain model of the ITS covered the following topics:

1. Data communication network architectures and protocols

2. Data communication and internet security

3. Wireless communication and mobile computing technologies

4. Data mining and security issues

\subsection{Student Model Architecture}

The student model architecture contains information concerning learners' cognitive and emotional level and their evaluation as learning progresses. Student model must be lively, so that it can provide the current knowledge about the student while using the ITS. Students model of an ITS keeps track of student's logs data details. It keeps the fundamental records of students for instance, it stores learners' name, student's identification numbers, scores, completed task, and lesson exercises tried.

\subsection{Tutoring Model Architecture}

In tutoring architecture, students use their identification number to register and login into the ITS so as to take lessons and solve task after each lesson (Izzeddin, Alshawwa, Mohammed, Samy, Abu, 2019). In tutoring model, students watch the video lesson and attempt the exercises related to the lesson for three times. Study conducted by Ahmad (2019) states that final score should be taken as final mark even if the final attempt to the exercises is less than the previous score. However, this tutoring model architecture provides that at the end of the third attempt to the exercises the system will take the average score of the three scores as the students' final mark. The tutoring architecture is designed to allow a student to read the lesson and attempt exercises only three times unlike the older generation of ITS, this is to encourage learners to take their study serious and to improve their performance as they know that they can only make three attempt. The student's progress flow diagram is shown if Fig 1 below.

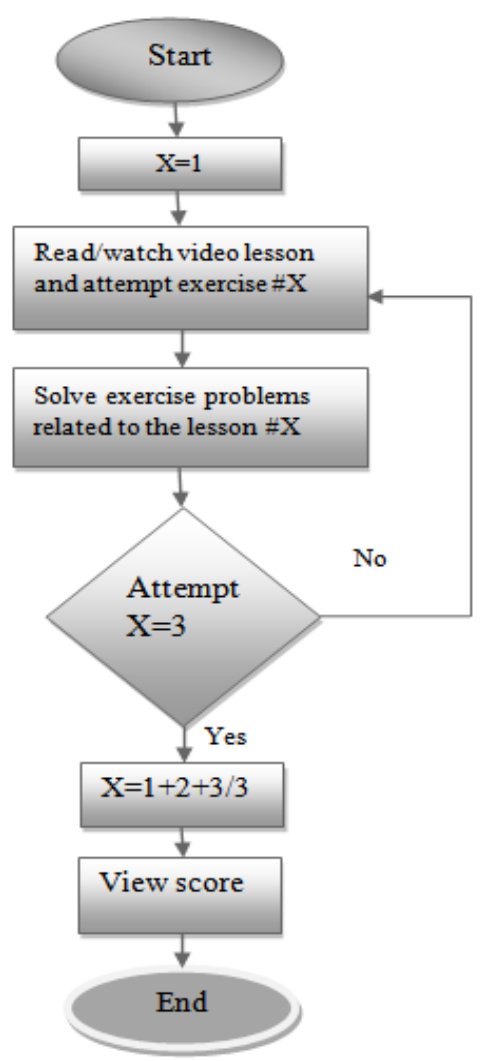

Figure 1. Student's progress flow diagram model 


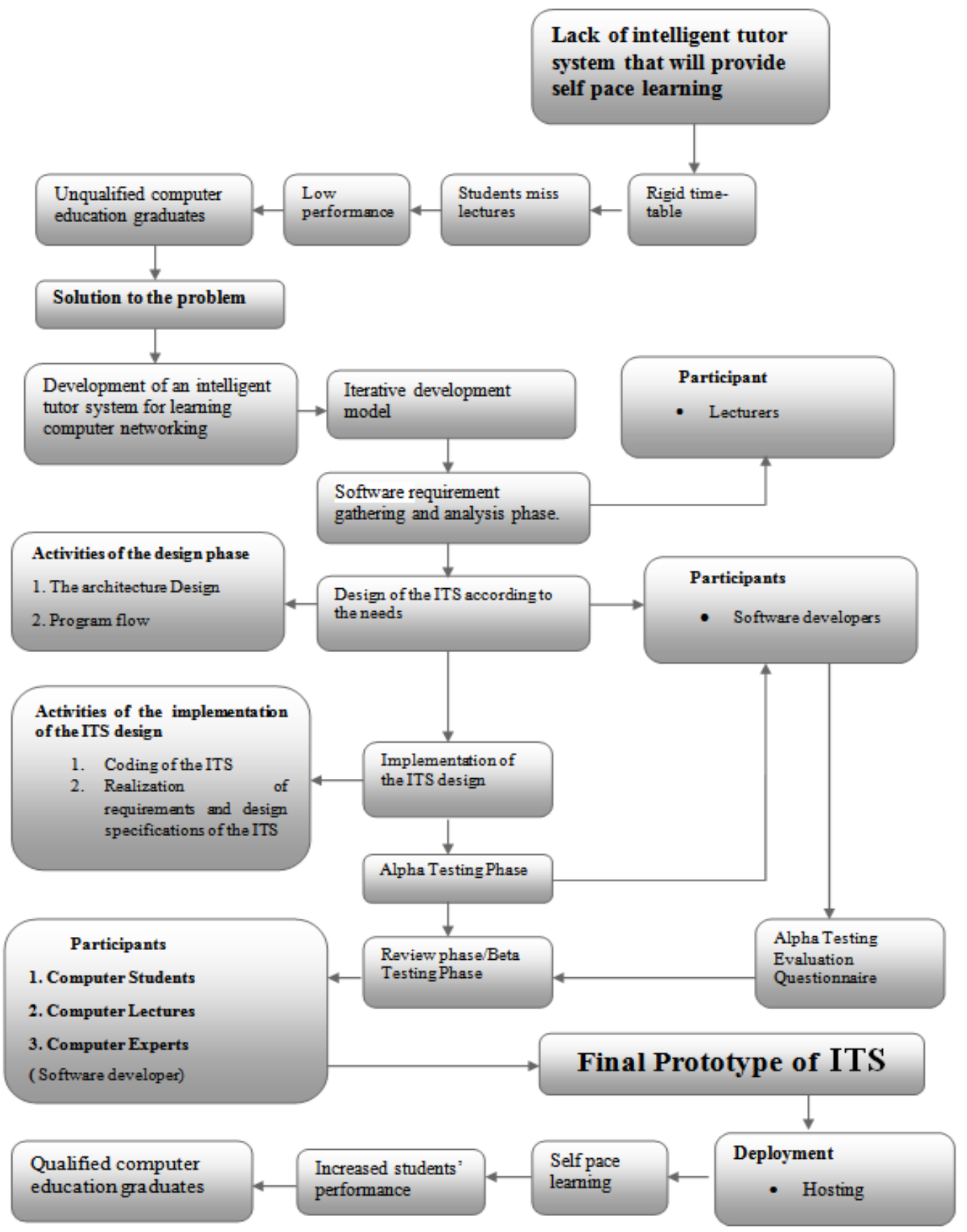

Figure 2. Schematic diagram of the proposed computer networking intelligent tutor system

\subsection{User Interface Model}

In the student interface, students are allowed to register and select preferred lesson to learn. Students architecture are presented with instruction on how to take the quiz problem, and a number of radio buttons among which one of them has the correct answer for this problem. Hence, in this tutor once the student is ready to start to answer the questions, instructions will be presented and a start button will be clicked. The time meant for the quiz and the remaining time will be shown. If a student wishes to visit the previous question as a result of doubt, previous question button will be click. At the end of the quiz, student will click submit button to networking-tutor, and the networking tutor then ask the student to confirm the submission. The "Hint" is invisible when students are attending to the exercises this is to encourage students think more about the solution of the problem. The schematic diagram of this proposed ITS is presented in Fig. 2 .

\section{Computer Networking}

Computer networking makes sharing files within a company, building premises and sharing ideas among 
students and teachers more easily (Jared 2016). Computer networking can be used between teachers and students and can improve interaction and engagement with learning resources. Computer networking is today offered as a course of study in computer science, computer science education, engineering courses and other related computer courses. This is because computer networking is today considered as an essential part of information technology (IT) systems. In view of this, students' learning content requirements for developing computer networking intelligent tutor system was evaluated based on: data communication network architectures and protocols, data communication and internet security, wireless communication and mobile computing technologies, data mining and security issues.

\section{Research Questions}

This study is focused on evaluating the software and architectural design requirement specifications for developing an intelligent tutor system for learning computer networking. Specifically the following research questions guided the study;

1. What are the software administrators' functional requirements for developing an intelligent tutor system?

2. What are the architectural user case design requirement specifications for developing an intelligent tutor system?

3. What are the students' learning content requirements for developing an intelligent tutor system?

\section{Methodology}

This study adopted survey research design. A survey research design is a design in which data are collected from a relatively number of people or items based on knowledge and experience. A survey research design is a systematic means of data collection from large group of people. It is also a data collection technique in which information is gathered from individual called respondents, by having them respond to questions. The reason for using a survey research design was that questionnaire was used to collect data concerning opinion of computer lecturers and software developers on the software and architectural design requirement specifications for developing an intelligent tutor system (ITS) for learning computer networking.

\section{Population for the Study}

The total population for this study is 89 . The population is distributed among computer lecturers (73), software developers (16). The total population of 73 lecturers from seven Universities in Nigeria (University of Nigeria, Nsukka, Enugu State University of Science and Technology, NnamdiAzikwe University Awka, Ebonyi State University, Godfrey Okeye University, Enugu, MichealOpkara University of Agriculture Umudike, Chukwuemeka Odumegwu Ojukwu University UliAnambra State) These lecturers were used to determine the software requirement specification and students' learning content requirements for developing an intelligent tutor system. The total population of 16 software developer from AppZone Group, from iNterra Networks, Process CARE, Bludel Technologies, Viratec Nigeria Limited, QUICKPROX Company were used to check and determine the appropriateness of the architectural design user case for developing an intelligent tutor system for learning computer networking.

The instrument used for the study is based on the software, architectural and students' requirements specifications. These instruments are software requirement administrators' functional requirement questionnaire, software architectural design questionnaire students' requirement specifications questionnaire. These questionnaires for data collection were based on 4 point rating scale; the instruments were validated by 3 experts in the field of ITS and two software developers.

\section{Method of Data Collection}

The software requirement specification and students' learning content requirements questionnaire was administered to 73 lecturers. The specifications were collected and used for the evaluation of the software requirement specification and students' learning content requirements of an intelligent tutor system. The software design evaluation questionnaire was administered to 16 software developers to check the architectural design of the ITS.

\section{Method of Data Analysis}

Data collected from lecturers and software developers was analyzed using mean and standard deviation. The decision rule for research question 1 to 3 was that items with mean scores of 2.5 and above was accepted while items with mean score below 2.5 was rejected as requirement specifications, architectural design specifications and students' learning content requirements specifications based on a 4 point rating scale.

\section{Result and Discussion}

The result and discussion of the findings of the study are presented in table 1 to 3 . 
Table 1. Software administrators' functional requirements for developing an intelligent tutor system

\begin{tabular}{|c|c|c|c|c|c|}
\hline S/N & $\begin{array}{c}\text { Administrators' Functional Requirements. } \\
\text { Administrator should be able to; }\end{array}$ & $\mathbf{N}$ & $\bar{X}$ & $\mathbf{S D}$ & Rem. \\
\hline 1 & View registered students & 73 & 2.92 & 0.98 & Highly Important \\
\hline 2 & Ban/unban students account & 73 & 2.84 & 0.93 & Highly Important \\
\hline 3 & Activate pending student account & 73 & 2.99 & 0.90 & Highly Important \\
\hline 4 & Add new lecturers account & 73 & 2.96 & 0.93 & Highly Important \\
\hline 5 & Chat with registered students & 73 & 3.03 & 0.99 & Highly Important \\
\hline 6 & Keep track of total user account & 73 & 2.88 & 1.10 & Highly Important \\
\hline 7 & Upload course lecture materials & 73 & 2.77 & 0.95 & Highly Important \\
\hline 8 & Edit/change ITS personality & 73 & 2.62 & 1.06 & Highly Important \\
\hline 9 & View conversation logs & 73 & 3.04 & 1.01 & Highly Important \\
\hline 10 & View database action & 73 & 2.90 & 0.90 & Highly Important \\
\hline 11 & Install modules. & 73 & 2.77 & 0.91 & Highly Important \\
\hline 12 & Configure the distribution map projection & 73 & 3.86 & 0.99 & Highly Important \\
\hline 13 & Remove a spatial layer to the distribution map & 73 & 2.95 & 0.97 & Highly Important \\
\hline 14 & View error logs & 73 & 2.53 & 1.08 & Highly Important \\
\hline 15 & Download error logs & 73 & 2.85 & 1.01 & Highly Important \\
\hline 16 & Add a spatial layer to the distribution map & 73 & 3.04 & 1.02 & Highly Important \\
\hline
\end{tabular}

Key: $\mathrm{N}=$ Number of Lecturers, Mean $=\boldsymbol{X}, \mathrm{SD}=$ Standard Deviation

The findings of this study on the administrators' functional requirements for developing an intelligent tutor system for learning computer networking showed that the entire enlisted requirement are highly important for developing an intelligent tutor system for learning computer networking. Hence, these results imply that the administrators' functional requirement specifications for developing an assistive intelligent tutor system for learning computer networking by computer education students as indicated by the computer education lecturers are appropriate and highly important.

Table 2.The architecture user case design requirement specifications for developing an intelligent tutor system

\begin{tabular}{|c|c|c|c|c|c|}
\hline S/N & Item statement & $\mathbf{N}$ & $\bar{X}$ & SD & Remark \\
\hline 1 & Students' should be able to register on the ITS & 16 & 4.19 & 0.83 & Absolutely Appropriate \\
\hline 2 & Students' should be able to LOGIN to the ITS & 16 & 3.75 & 1.24 & Appropriate \\
\hline 3 & View received video lesson and send response & 16 & 3.88 & 1.20 & Appropriate \\
\hline 4 & $\begin{array}{c}\text { Software Design tools for the ITS (HTML, JAVASCRIPT, } \\
\text { PHP, CSS). }\end{array}$ & 16 & 3.88 & 0.96 & Appropriate \\
\hline & Grand Mean & & $\mathbf{3 . 9 3}$ & $\mathbf{1 . 0 6}$ & Appropriate \\
\hline
\end{tabular}

Key: $\mathrm{N}=$ Number of Software developers, Mean $=\bar{X}, \mathrm{SD}=$ Standard Deviation

The data analysis presented in table 2 above shows that all the 4 items on the architecture design are for the intelligent tutor system based on the software requirement specification, shows that these software design tools-HTML, JAVASCRIPT, PHP, CSS are highly appropriate good programming language for developing a user case interface, user interface, web page and hosting the intelligent tutor system on a website. This implies that opinion of the software developers are not far apart. Therefore, these items on the architectural design appropriate for the intelligent tutor system based on the software requirement specification as identified by software developers are appropriate and accepted.

Table3. Students' learning content requirements specifications for developing an intelligent tutor system

\begin{tabular}{|c|c|c|c|c|c|}
\hline S/N & Students' learning content should include: & $\mathrm{N}$ & $\overline{\boldsymbol{X}}$ & $\mathrm{SD}$ & Rem. \\
\hline 1 & Data communication network architectures and protocols & 73 & 2.86 & 0.93 & Excellent \\
\hline 2 & Data communication and internet security & 73 & 2.90 & 0.90 & Excellent \\
\hline 3 & Wireless communication and mobile computing \\
technologies & 73 & 2.77 & 0.91 & Excellent \\
\hline 4 & Data mining and security issues & 73 & 3.05 & 0.88 & Highly Excellent \\
\hline
\end{tabular}

Key: $\mathrm{N}=$ Number of lecturers, Mean $=\boldsymbol{X}, \mathrm{SD}=$ Standard Deviation 
The result of the students' learning content requirement specifications as indicated by computer education lecturers showed that all the enlisted requirements for developing computer networking intelligent tutor system are excellent. All the enlisted items obtained a mean score that is higher than 2.5. This implies that opinions of the lecturers on the students' learning content are accepted and excellent for developing computer networking intelligent tutor system.

\section{Conclusions}

In this study, the software and architectural requirements specifications appropriate for developing an intelligent tutoring system has been analyzed by teachers and software developers. The findings revealed that lecturers accepted students' learning content requirements. In this paper, the ITS software requirements administrators' requirements, architectural user case design specifications and students learning content requirements enlisted are important and appropriate for developing an intelligent tutor system for learning computer network. Therefore, it is essential for current ITS not to have only relevant information about students but consider the software administrators' functional requirements for developing an intelligent tutor system, the architectural user case design requirement specifications for developing an intelligent tutor system and the students' learning content requirements for developing an intelligent tutor system; by this, individual learning needs can be taken care of and increases students' academic performance.

\section{Acknowledgments}

The researchers would like to bestow an acknowledgement to Dr. Ifeoma Bernadine Onah and all the co-authors from the Department of Computer and Robotic Education, Faculty of Technical and Vocational Education, University of Nigeria, Nsukka, who all supported this research.

\section{REFERENCES}

[1] Rabiman., R. Muhammad., N. Nur., K. (2020). Design and Development E-Learning System By Learning Management System (LMS) In Vocational Education. International Journal of Scientific \& Technology Research, (9)1, ISSN 2277-8616, www.ijstr.org.

[2] Ariel, P. (2020). Assistive Technology and Software to Support Accessibility, Journal of Medical Reference Services Quarterly, 39:2, 203-210, doi: $10.1080 / 02763869.2020 .1744380$

[3] Ali, K. E \& İsmail, Ç. (2020). Design framework of adaptive intelligent tutoring systems. Education and Information
Technologies, part of Springer Nature 2020.https://doi.org/10.1007/s10639-020-10182-8.

[4] Viberg, O., \& Grönlund, Å. (2017). Understanding students' learning practices: Challenges for design and integration of mobile technology into distance education. Learning, Media and Technology, 42(3), 357-377. https://doi.org/10.1080/1 7439884.2016.1088869.

[5] Irin, S., Plass, J. L., Homer, B. D., Vatanartiran, S., \& Tsai, T. (2018). Digital game-based education for Syrian refugee children: Project hope. Vulnerable Children and Youth Studies, 13(1), 7-18. https://doi.org/10.1080/17450128.201 7.1412551 .

[6] Taub, M., \&Azevedo, R. (2019). How does prior knowledge influence eye fixations and sequences of cognitive and metacognitive SRL processes during learning with an Intelligent Tutoring System? International Journal of Artificial Intelligence in Education, 29(1),1-28. https://doi.org/10.1016/j. learninstruc.2019.04.001..

[7] Onah, B.I., Ezenma, B.C., Ariyo, O. S., Jimoh, B., Omeje, H.O., Okereke, G.K.O., Ogbonna, G.N., Damian, K.O and Mukoro, E.E. (2020). Assessment of Computer Networking Needs of Students of Computer Education and Industrial Technical Education for Improving Academic Performance in Nigerian Universities. Journal of Engineering and Applied Sciences, 15(11) 2020, pp. 2464-2472. doi: jeasci.2020.2464.2472.

[8] Sodhro, A.H.; Luo,Z.; Sangaiah, A.K.; Baik, S.W. (2018) Mobile edge computing based QoS optimization in medical healthcare applications. International Journal of Information Management. Volume 45, April 2019, pp 308-318. https://doi.org/10.1016/j.ijinfomgt.2018.08.004.

[9] Jiragorn, C., Prachyanun, N., Panita, W. (2019). Analysis of an Intelligent Graphical Tutoring System Using the Internet of Things (IoT) to Develop the Competency of Embedded Systems. International Journal of Online and Biomedical Engineering. 15(4), https://doi.org/10.3991/ijoe.v15i04.951 1 .

[10] Maiga, C; Giuseppe D,' A; Matteo, G; Francesco, O; Demetrios, S; Carmine, S; (2020). Building Ontology-Driven Tutoring Models for Intelligent Tutoring Systems Using Data Mining, IEEE Access, volume 8, 2020, DOI: 10.1109/ACCESS.2020.2979281.

[11] Mones, M. A, Mohammed, Z. S, Samy, S A. N. (2017). Learning computer networks using intelligent tutoring system. International Journal of Advanced Research and Development. 2(1), 74-78. Retrieved on $16^{\text {th }}$ April, 2019 from

https://www.researchgate.net/publication/314229691_Learn ing_computer_networks_using_intelligent_tutoring_system

[12] Ali, T. Q .al-., Ahmed, Y.F. S., Basma, J. S. (2018). Design and Evaluate the Effectiveness of the Networking Tutor, Intelligent Tutoring System for Teaching Students an Introduction for Computer Network in Iraq. Journal of Scientific and Engineering Research, 2018, 5(10):43-48. https://www.researchgate.net/publication/328676892.

[13] Karsten, W., (2019). PQtutoraquasi-intelligent tutoring system for quantitative problems in General Chemistry, ChemistryTeacherInternational.2019;20180009, DOI:10.1515/cti-2018-0009. 
[14] Santiago, S., Cristian, G., David, V., Carlos, G., Miguel Á, R. (2020). An Intelligent Tutoring System to Facilitate the Learning of Programming through the Usage of Dynamic Graphic Visualizations. Journal of applscience, Appl. Sci. 2020, 10, 1518; doi:10.3390/app10041518.

[15] Daniel, W., Erik, H., Kenneth, R. K. (2020). An Interaction Design for Machine Teaching to Develop AI Tutors, CHI '20, April 25-30, 2020, Honolulu, HI, USA, ACM ISBN 978-1-4503-6708-0/20/04, http://dx.doi.org/10.1145/ 3313831.3376226 .

[16] Onah, B.I., Ezenma, B.C., Ariyo, O. S., Jimoh, B., Omeje, H.O., Okereke, G.K.O., Ogbonna, G.N., Damian, K.O and Mukoro, E.E. (2020). Assessment of Computer Networking Needs of Students of Computer Education and Industrial Technical Education for Improving Academic Performance in Nigerian Universities. Journal of Engineering and Applied Sciences, 15(11) 2020, pp 2464-2472. doi: jeasci.2020.2464.2472.

[17] Suryanto, N., Sigit, H. W, and Luqman, H. (2017). Comparative Analysis of Software Development Methods between Parallel, V-Shaped and Iterative. International Journal of Computer Applications. IJCATM: Retrieved on 15April, 2019, pp8. (169)11, 8. DOI: 10.5120/ijca2017914605.

[18] Marakas, J. A. O'Brien, G. M. (2010). Management information systems (10th ed.). New York: McGraw-Hill/Irwin. (pp. 485-489). ISBN 0073376817. https://www.amazon.com/Management-Information-Syste ms-James-OBrien/dp/0073376817.

[19] Control and Audit, Information Systems. SDLC. (2013). Institute of Chartered Accountants of India. (528) 19. Retrieved on $9^{\text {th }}$ june, 2020 from https://mastermindsindia.com/RTP\%20MAY\%2016-II.pdf.
[20] Yan, T., \& Wong, T. (2016). Software Development Life Cycle. Retrieved on $16^{\text {th }}$ December, 2018 from http://www.cse.ust.hk.Software Development Life Cycle.

[21] Nikolaj, T. G.M; Alke; M. (2020). General ITS architecture and framework. 16th International Conference, ITS 2020, Athens, Greece, June 8-12, 2020, pp 17-22, doi: 10.1007/978-3-030-49663-0_3

[22] Fehaid, A. \&Naeem, R. (2019). Comparison and Efficacy of Synergistic Intelligent Tutoring Systems with Human Physiological Response. (p.4.), http://doi:10.3390/s1903046 $0, \mathrm{p} .4$.

[23] Kee, D. (2011). Educational Robotics-Primary and Secondary Education. IEEE Robotics \& Automation Magazine, 18(4), 16-19. Retrieved on $126^{\text {th }}$ August, 2018 from: https://ieeexplore.ieee.org/xpl/tocresult.jsp?isnumber $=6096005$.

[24] Ahmad; M. M. (2019). Intelligent Tutoring System for Teaching Introduction to Computer Science in Al-Azhar University, Gaza, Faculty of Engineering \& Information Technology, DOI: 10.13140/RG.2.2.33473.61289.

[25] Izzeddin, A.; Alshawwa, Mohammed A.; Samy, S.; Abu, N. (2019). An Intelligent Tutoring System for Learning Computer Network CCNA. International Journal of Engineering and Information Systems (IJEAIS), (3)2, 28-36. Retrieved on $1^{\text {st }}$ March, 2019 from http://ijeais.org/wp-cont ent/uploads/2019/02/IJEAIS190204.pdf

[26] Jared, E (2016). What-are-advantages-of-computer-network s. Retrieved on 12 April, 2020 from: https://www.quora.co $\mathrm{m}$ /What-are-computer-networks-What-are-the-advantages-a nd-disadvantages 